\title{
CURRENT BIOETHICAL ISSUES IN PARASITOLOGY
}

\author{
BOURY D.* \& DEI-CAS E.**
}

\section{Summary:}

Parasitic diseases constitute the most common infections among the poorest billion people, entailing high mortality rates and leading to long-term infirmities and poverty. Although the setting-up of public health programs implies many ethical consequences, the range of specific questions in parasitology that can be attributed to bioethics remains, to a large extent, unexplored. From the present analysis, it emerged three main issues which characterize ethical stakes in parasitology: accounting the complexity of the field of intervention, putting the principle of justice into practice and managing the changing context of research. From the research angle, medical parasitology-mycology, as other biological disciplines, is undergoing tensions derived from biological reductionism. Thanks to its links with the history and philosophy of the sciences, bioethics can help to clarify them and to explain the growing hold that technologies have over scientific thinking. On the whole, researchers as well as clinicians are called on to assume a specific responsibility, proportional to their competence and their place in the making of scientific, health, economic and social decisions.

KEY WORDS : parasitology, ethics, bioethics, public health, responsibility.

S ince the seventies, bioethics has become the field of ethics devoting a particular interest to technoscientific practices as they are applied to the living being and more specifically to the human living being. It has been defined as "generally multi-disciplinary research, discourses and practices as a whole, whose objective is to clarify or solve ethically-oriented issues arising from advances in and applications of the medical techno-sciences" (Hottois \& Parizeau, 1993). This field, named bioethics by the American biochemist Van Rensselaer Potter in a book entitled Bioethics: Bridge to the future, published in 1971 in the United States, is evolving in a context influenced by a weakening of moral guidelines, by mutations in conditions of basic research practice and by globalisation of the economy.

\footnotetext{
* Centre of Medical Ethics, Catholic University of Lille, EA4031, Catholic University of Lille \& Lille 2 University, France.

** Parasitology-Mycology Service, Microbiology Department, EA3609 Faculty of Medicine, Lille 2 University Hospital Centre \& IFR-142 Lille Pasteur Institute, France.

Correspondence: Dr Eduardo Dei-Cas, Lille Pasteur Institute, 1, rue du Pr-Calmette BP245, F-59019 Lille, France.

Tél: +33 (0)32087 7155 - Fax: +33 (0)32044 4895.

E-mail: eduardo.dei-cas@pasteur-lille.fr
}

Over about 40 years, numerous works have been published on bioethics, regulatory and control organisms have been put in place, texts modifying legal and statutory dispositions on both the national and international levels have been adopted. Bioethics has therefore quickly become a component for structuring research activities and clinical practices in all disciplines and for all health professionals.

\section{WHY BIOETHICS IS NEEDED IN MEDICAL PARASITOLOGY}

Th $\mathrm{n}$ the field of parasitology, the range of questions that can be ascribed to bioethics yet remains, to a large extent, unexplored. The number of publications specifically devoted to the ethical issues that could arise through developments in parasitology as a science and the setting-up of control procedures against parasitic illnesses is still rather poor. And yet parasitology constitutes a field of action and collective reflection just as rich as any other field of biomedical science and clinical action.

Selgelid (2005) wonders why the bioethical approach is so rare in microbiology (including medical parasitology and mycology). The reasons given refer to the prime motivations of bioethics, to the dominating features of biomedical thinking when it first emerged and to the falsely "exotic" character of parasitic illnesses. On the one hand, bioethics has become an autonomous discipline whose main role is to supply answers to questions raised by advances in biomedical sciences and techniques. It thus gives considerable importance to progress in bio-technology and its applications (gene therapy, stem cells, cloning, in vitro fertilization, preimplantation genetic diagnosis, etc.) and to the resulting controversies (embryo status, euthanasia, patentability of the living being, etc.). Nevertheless, it has less interest in problems raised by supposedly "known" illnesses, such as infectious diseases (Selgelid, 2005). It is true that bioethics emerged at a time of great medical optimism when we had managed to control a number of infections, and even, for the first time in history, to 
eradicate an infectious disease, smallpox. Health authorities and the medical community were ready to wager that the control of major endemics was irreversibly mastered, as the economic and social advances of the $60 \mathrm{~s}$ and $70 \mathrm{~s}$, especially in developed regions of the world, led them to hope for a sharp decrease in their impact. On the other hand, these diseases often have an "exotic" character. They seem to belong to "others", to poor populations in developing countries (Selgelid, 2005) or subjects severely weakened by cancer, immuno-suppressing treatment or AIDS. In such cases, the injustice is so obvious that it must be combated without specific ethical questions being raised.

For these reasons, the range of infectious and parasitic diseases as well as public health programmes dealing with them is rarely the object of bioethical reflection (Selgelid, 2005). They are hardly ever considered as public health priorities (except perhaps malaria) and so they can more and more frequently be labelled as neglected diseases. And nevertheless, they constitute the most common infections among the 2.7 billion people who live on less than $\$ 2$ a day, causing about 534,000 deaths a year in such populations and leading to long-term infirmities and poverty. Globally, the only malaria is responsible for 273 million cases worldwide and causes 1.12 million deaths annually (TDR, 2004). This endemic disease decreases economic growth in sub-Saharan African countries by as much as $1.3 \%$ per person per year, interferes with children's mental and physical development and affects national economies (Dowell \& Levitt, 2002). In short, parasitic diseases constitute the greatest health problem in the developing countries (Hotez et al., 2007). The link with the principle of justice, one of the main principles in bioethics, is obvious, as this principle goes beyond the problems of distributive justice among the citizens of a nation to reach the international level, showing particular interest in inequalities between the human communities of developed regions and the more vulnerable ones of developing regions.

However, parasitic and fungal diseases also represent an ethical and public health issue in other areas. This affirmation can be adequately illustrated by considering the problem of emergent or re-emergent infections, i.e. "diseases of infectious origin whose incidence in humans has increased within the past two decades or threatens to increase in the near future" (US Centers for Disease Control and Prevention). Interestingly, emergent or re-emergent pathogens have worldwide distribution and represent a recognized public health issue in developed areas. Actually, immunosuppression, AIDS and hospitalisation, conditions largely present in these areas, are much more important favouring factors of emerging or re-emerging infection than pathogen genetic mutation, globalisation or climate change (Woolhouse et al., 2006). Specifically in medical parasitology or mycology, emerging or re-emerging agents have a considerable impact in both developing and developed areas. Thus, 13 (25\%) species of protozoan pathogens cause emerging or re-emerging infections, and six of these 13 species are recognized pathogens in developed areas. Likewise, though only $7 \%$ of pathogenic fungi are responsible for this type of infections, the number of emerging or re-emerging pathogenic fungal species is higher in Europe than in Africa (15/22 in Europe, 12/22 in Africa) (Woolhouse et al., 2006).

Tensions between the establishing of measures of hygiene, feeding and ways of life essential to the prevention of parasitic diseases and the customs and cultural, social and symbolic traditions of communities (whether they be rich or poor) are typical bioethical issues which concern medical parasitology. It is well-known that some parasitic cycles thrive on habits which are deeply rooted among the populations of endemic regions. For example, in regions of high hydatic endemic disease in South America, sheep-breeding is widespread and so dogs are essential. Peasants in these areas maintain the "ancestral" custom of sacrificing sheep in non-protected places and using their offal, especially their lungs, often infected with Echinococcus larvae, to feed their dogs. In Canada, Indians infect their dogs by feeding them the lungs of moose and caribou (Neva \& Brown, 1994), which are also Echinococcus granulosus intermediate hosts. Similarly, anisakiasis, a common disease in Japan ( $90 \%$ of cases worldwide) caused by nematode larvae ingested alive in raw or badly cooked fish, could be avoided by freezing fish meant for consumption at $-20^{\circ} \mathrm{C}$ for more than 24 hours (DeiCas, 1996; Chai et al., 2005). However, as populations are highly resistant to any changes in habits, the prevalence of these two diseases is still significant in their respective endemic regions. A sustained effort in developed health education, in a bioethical perspective, is the only way to attain a rational acceptation of the preventive measures to be set up and to appease the tensions which are likely to be associated. Bioethics could therefore assist in regulating tensions between research efforts on anisakiasis and fishermen's fears that their turnover will slump with the publication of research data in the gutter press.

\section{MEDICAL PARASITOLOGY AND BIOETHICAL THINKING}

r $\mathrm{n}$ a public health perspective, all actions targeting parasitic and fungal diseases have to take into account the economic and social context, the cultural level of the population and the institutional and political background. Indeed the responses required 
are so complex that a multi-disciplinary approach appears to be essential. Bioethics can facilitate this kind of approach as, faithful to its practice (Tausig et al., 2006), it favours the implication of the social sciences (history, anthropology, sociology, political sciences, economics and geography).

Bioethics is in fact a multi-disciplinary subject, the rules of which have emerged from exchanges between different systems of value (ethical, philosophical, religious), regulated within the appropriate jurisdictions (e.g. "ethical committees"). Its multi-disciplinary character and inter-professional exchanges are coherent with the specificity of parasitology as a field of knowledge. Thus, parasitic pathologies are varied and complex, they may apply to any system in the organism and result in usually non-specific symptoms. The physician ends up requiring data produced by the clinical laboratory scientist to establish a diagnosis with certainty. The laboratory technician has a key role, often poorly recognised, to play in this process. Incidentally, it can be noted that there is often a shortage of well-trained technicians in developing regions which are precisely the most affected by parasitic and fungal endemics. Above all, the clinical expression and epidemiology of parasitic diseases vary along with the kinetics of the development of agents in the organism, in reservoir animals (zoonotic parasitosis), in arthropod or other vectors (vector-borne parasitic infections) and in the environment (soil- or water-borne parasitic infections). Widespread competence is required to be able to understand these illnesses. For example, notions of zoology (to understand the biology of vectors, reservoirs, wild hosts), of ecology (parasite life cycles are mostly linked to specific ecosystems) and of microbiological environmental control are often essential in parasitology. The opening-up of this discipline to other ways of thinking is consistent with the multiplicity of approaches required in bioethics and should make it easier to bring together these two fields of knowledge.

\section{FROM RESEARCH TO CLINICAL FIELD: THE ETHICAL RESPONSIBILITY OF PARASITOLOGISTS}

I

nvolved in producing knowledge and mastering technological tools, researchers and clinicians have a major responsibility throughout the process which starts with research and leads to practical application. This responsibility of course focuses on the technoscientific level (mastering fundamental knowledge, technical tools and clinical applications). However, at the same time, it is present in the specific economic and social context in which the parasitologist, researcher or clinician, must for example assess technical innovations, make a detailed estimation of the potential involvements of their application and decide whether it is worth introducing them into public health actions. In this context, the term "technical innovation" may imply a technological platform or quite simply a new diagnostic kit, a new laboratory robot, a novel medicine, and so on.

Thus, the parasitologist's responsibility is not only technoscientific: there is an ethical component to it which does not simply consist in respecting statutory texts and bioethical rules. Bioethical responsibility also means thinking on how parasitology is developing and more particularly on the need to extend and promote, in an increasingly difficult context, basic biology research in parasitology or mycology, and to examine, from a critical point of view, the factors involved when defining the priority modalities and topics of research. Finally, the parasitologist must ensure the durability of his ethical responsibility by transmitting the conditions and particularities of his practice to $\mathrm{PhD}, \mathrm{MSc}$ and other students whose training he is in charge of.

\section{BIOETHICAL ISSUES IN MEDICAL PARASITOLOGY}

Three main questions arise from analysing the bibliography:

1 - Complexity of the field of intervention: accounting for the complexity of parasitic diseases and for the factors determining their endemic existence in any given population, as well as the outbreak of clustered cases and of epidemics, calls for complex models of nonlinear dynamic systems rather than those of the univocal determinism of linear systems (Sève, 2005). These factors involve the relationship that human groups entertain with the fauna, flora, countryside - that is, their connection to the space and temporality of ecosystems. Control strategies will therefore have to take into account the inevitably dynamic and multi-factorial feature of causal chains. In this perspective, reduction as an analysing strategy often proves to be inadequate as the properties of ecosystems cannot be deduced from those of components taken separately.

In the same way, targeting a population as a whole rather than the most vulnerable groups therein, has proved to be more conclusive in assessing the effectiveness of insecticide-treated nets (ITN) in preventing malaria (Killeen et al., 2007). A conventional biomedical approach would almost certainly have targeted the most vulnerable populations. However, it would not have taken into account the impact of the use of ITNs on the entire malaria-endemic population or the behaviour of Anopheles vectors. It would have neglected the fact that a generalised use of ITNs over a period 
of years protects not only the vulnerable groups (pregnant women, young children) but also other groups, even those made up of non-users of ITNs. In fact, as ITNs kill adult Anopheles directly and oblige them to undertake longer, more hazardous foraging expeditions in search of vertebrate blood and aquatic habitats to lay their eggs, the number of infectious bites per person and per year is significantly reduced (Killeen et al., 2007). In addition, targeting all age groups bypasses the inevitable inadequacies of selective targeting (leakage, inequity). Finally, the authors ask a key question: "How can such population-wide coverage levels be affordably and cost-effectively sustained?", as it illustrates the articulation of the analysing strategy (entire malaria-endemic populations versus vulnerable sub-groups), epidemiology in a zone with a high transmission rate, prevention strategy and the social-economic context. The complexity of the field of action is to be found in the coexistence of several, often competing and sometimes contradictory logics (scientific, health, political, commercial) which form the framework of the research and clinical fields and generate tensions which are not specific to the field of parasitic diseases and should be approached bioethically.

2 - On the principle of justice: an examination of publications indicates that most of the questions posed by research, discovery (e.g. of emerging illnesses), detection, treatment, caring for and prevention of the main parasitic diseases refer to the general issue of justice. In the North American version of bioethics, systemised by Beauchamp \& Childress (2001) alongside the principle of autonomy (respect for a person's self-determination) and the principles of doing good and not evil (aiming at well-being and avoiding any unnecessary harm), the principle of justice constitutes "the moral obligation to divide medical resources equitably in the same way as the benefits and risks of medical conduct" (Benaroyo, 2006). Numerous publications assess the cost/benefit ratio of the preventive or curative treatments proposed; some seek new collaborative conditions between private industry, international institutions and local political powers; others evoke the signing-up conditions of health workers in the case of an epidemic. All the constraints mentioned and failures registered seem to oblige us to look again at these difficulties from the angle of the principle of justice; not limited to individual justice but extended to international, national and local justice. The objective to reach "the bighest attainable standard of health" (Hunt, 2006) sums up the intentions of the international community, but requires the mobilising of new competences and new strategies including how to select priorities, how to decide on possible compromises and how to assess the impact of health programmes.

Major projects for fighting against infectious and parasitic diseases - IAVI (International AIDS Vaccine Ini- tiative); MMV (Medicines for Malaria Venture); Global Alliance for TB Drug Development - associating public institutions and private partners, are one of the means dominating public health interventions in developing countries (Wheeler \& Berkley, 2001). Is it feasible, at the different evaluation stages of these interventions, to assess their content, their methodology and their results from an ethical angle? If so, criteria offering the possibility to measure the quality of communities' participation and the progress made in justice could be added to those of medical effectiveness and economic efficiency.

In short, if we do not want the application of the principle of justice to appear as a sort of disguised paternalism ("we are debating among ourselves what is right for you"), communities and populations in developing countries must be acknowledged as actors in their own right. The bioethical approach should favour training, decision-making, control and assessment by communities themselves who are often requested to help in the public health struggle against parasitic diseases.

3 - A changing research context. From the research angle, medical parasitology-mycology is undergoing the same tensions as other biomedical disciplines. These are the result of confrontation between descriptive methods based essentially on morphology, clinical description and on-the-spot practice, and approaches which privilege the molecular characterisation of agents based on knowledge of parasites or pathogenic fungi' genomes and as well as on a precise determination of the host's immune response, something that has benefited from recent advances in immunology. Novel approaches claim to be closer to therapeutic or preventive interventions or even to associate a very basic dimension (that of the genome) to objectives which appear to be very near to on-the-spot practice (PCR techniques to detect parasites and fungi both in the host and in the environment, identification of new therapeutic targets, recombinant protein vaccines, DNA vaccines, transgenesis of vectors to inactivate their ability to transmit pathogens, etc.). Although old and new approaches are obviously complementary (morphology was and still remains essential when dealing with parasitic cycles and for an understanding of the transition between different stages, whereas molecular methods, especially transcriptomic approaches, will doubtless assist in accounting for the mechanisms of such transitions), their apparent opposition has engendered tensions between old and new generations of researchers. The present renewal of interest in structural approaches, encouraged by technological advances (confocal microscopy, atomically-powered microscopy, etc.) linked to the emergence of outstanding bioinformatic methods, which ensure more and more detailed mastery of cellular imagery, nevertheless illustrates the remarkable comeback of the morphological sciences. Thanks to its links 
with the history and philosophy of the sciences, bioethics can help to explain the growing hold that techniques have over science, especially the impact of certain technical corpus such as for example that of molecular techniques ("molecular biology"), over project conception and scientific thinking.

If we look more closely, the question of reduction as a research strategy (Mahner \& Bunge, 1997) and its inability to grasp the emergence and complexity of the living being (Sève, 2006), also affect parasitological research (Boury et al., 2005). In fact, what alternative to reduction exists to characterise parasitic systems? The present crisis in basic biology is clearly current in the field of Parasitology-Mycology despite a few attempts to avoid either conventional reductionism or too speculative holism (Anderson \& May, 1991; Levin, 1996; Hoberg, 1997; Dujardin \& Dei-Cas, 1999). However, the predominant reply to this question is only biotechnological for the moment: high-speed biology, the "omics" (transcriptomic, proteomic, metabolomic approaches) which propose restoring the living being atomised by three centuries of reductionism. We are however entitled to question the justification of a living being reconstructed with jigsaw pieces that result from reductionist research.

\section{SOME IDEAS TO CONCLUDE}

$\mathrm{F}$ ew biological disciplines illustrate as parasitology does, how man belongs to the ecosystems. It explains how he contracts parasitoses related to his role either as a consumer in the ecosystems (e.g. distomatoses, taeniasis, trichinosis, anisakiasis), as a prey in the micro-predation practised by haematophagous vectors, or by ingesting infectious forms from the environment (oocyts, cysts, worm eggs and larvae). The latter then reach the ground where they are carried by rainwater, running water and irrigation, and thereby contaminate foodstuffs. Parasitology thus creates the image of a man totally integrated into trophic networks, entirely dependent on the flow of matter and energy of ecosystems, sharing advantages, risks and pathologies with non-human organisms. Inversely, the common representations of human daily life, those broadcast by advertising, the media and even by education, show a humanity which has somehow, thanks to historical and techno-scientific evolution, "escaped" from the ecosystems. It either witnesses, as an admiring spectator, nature reduced to bi-dimensional landscapes, lacking in depth, where the organisms inhabiting these landscapes are nothing but empty icons, or it considers "nature" to be a source of matter and energy exterior to mankind and virtually inexhaustible, even if political ecology has dramatically pointed out the limits and dangers of such triviality.
In truth, societies are faced with notions of risk and uncertainty. "Risks have taken on mighty dimensions, to the point that questions can be asked about the life itself of the buman species on earth; and this at the very moment when we are becoming aware of a sort of powerlessness in our will for technical power to have complete control over itself; so that risk today finds itself surrounded by a halo of uncertainty corresponding to what we know we are ignorant of. It is from this return to uncertainty that the call for responsibility finds its expression today" (Ewald, 1997).

Researchers as well as clinicians are called on to assume a specific responsibility, proportional to their competence and their place in the making of scientific, health, economic and social decisions. In this way, they can help citizens, as well as political and institutional heads, to have a better understanding of the complex mechanisms of parasitic endemic diseases, the foreseeable consequences and risks of decisions made, and to shed light objectively on public health issues. International journals are increasingly taking into account the ethical issues raised by the tropical diseases and pathologies to be found in developing countries; this acts as an encouragement to pursue this path (Chan, 2007). Rather than letting ourselves become prisoners through fear of tomorrow or fear of others, but without turning to the smug optimism of all-powerful science and technology, room should quite simply be reserved for a sort of ethical uneasiness, "like a goad which keeps us on the alert, preventing us from ever finding absolute rest" (Corcuff, 1997).

\section{ACKNOWLEDGEMENTS}

his project was developed in the framework of EA3609 Research Program "Presence and circulation of eukaryotic pathogens in ecosystems" supported by French Ministry of Research, Lille 2 University, and Lille Pasteur Institute.

\section{REFERENCES}

ANDERSON R.A. \& MAY R.M. Infectious diseases of humans: dynamics and control. Oxford University Press, Oxford, UK, 1991.

Beauchamp T. \& Childress J. Principles of Biomedical Ethics. Oxford University Press, Oxford, UK, 2001.

Benarroyo L. Ethique et responsabilité en médecine. Collection Médecine Société. Médecine et Hygiène, Genève, 2006.

Boury D., Deschamps C., Menozzi F., Raze D., VandenbunDer B., De Bouvet A. \& Dei-Cas E. Recherche biomédicale : le débat autour des notions de réduction et d'émergence. Annales de Biologie Clinique, 2005, 63, 573-579. 
Chai, J.Y., Darwin M.K. \& Lymbery A.J. Fish-borne parasitic zoonoses: status and issues. International Journal of Parasitology, 2005, 35, 1233-1254.

Chan M. A turning point in the history of the oldest diseases: Guest commentary by WHO Director-General Margaret Chan. Plos Neglected Tropical Diseases, 2007, 1, e65.

Corcuff P. De l'heuristique de la peur à l'éthique de l'inquiétude - Penser avec Hans Jonas, in: De quoi sommes-nous responsables ? Ferenczi T. (éd.), Le Monde-Éditions, Paris, 1997, 40-47.

DeI-CAs E. Larva migrans. Encyclopédie Médico-Chirurgicale (Paris, France), Maladies Infectieuses, 1996, 8-518- $A-10$, $16 \mathrm{p}$.

Dowell, S.F. \& LevitT A.M. Protecting the nation health in an era of globalization. CDC's Global Infectious Disease Strategy. CDC report, Atlanta, Georgia, 2002.

Dujardin L. \& DeI-CAS E. Towards a model of host-parasite relationships. Acta Biotheoretica, 1999, 47, 253-266.

Ewald F. L'expérience de la responsabilité, in: De quoi sommes-nous responsables? Ferenczi T. (éd.), Le MondeÉditions, Paris, 1997, 11-36.

Hoberg E.P. Phylogeny and historical reconstruction: hostparasite systems as keystones in biogeography and ecology, in: Biodiversity. II: understanding and protecting our biological resources. Reaka-Kudla M.L., Wilson D.E. \& Wilson E.O. (eds), Joseph Henry Press, Natl. Acad. Sci., Washington DC, 1997, 243-261.

Hotez P.J., Molyneux D., Fenwick A., Kumaresan J., Ehrlich S., SACHS J.D. \& SAVIOLI L. Control of neglected tropical diseases. New England Journal of Medicine, 2007, 357, 1018-1027.

Hottois G. \& Parizeau M.H. Les mots de la bioéthique. Un vocabulaire encyclopédique. De Boeck, Bruxelles, 1993.

HunT P. The human right to the highest standard of health; new opportunities and challenges. Transaction of the Royal Society of Tropical Medicine and Hygiene, 2006, 100, 603607.

Killeen G.F., Smith T.A., Ferguson H.M., Mshinda H., Abdulla S., LENGELER C. \& Kachur S.P. Preventing childhood malaria in Africa by protecting adults from mosquitoes with insecticide-treated nets. PLoS Medicine, 2007, 4, e229.

LEVIN B.R. The evolution and maintenance of virulence in microparasites. Emerging Infectious Diseases, 1996, 2, 93102.

Mahner M. \& Bunge M. Foundations of Biophilosophy. Springer, Berlin, 1997.

Neva F.A. \& Brown H.W. Basic clinical parasitology. Prentice Hall International Inc, London, 1994.

PotTer V.R. Bioethics: Bridge to the future. Prentice-Hall Pub, Englewood Cliffs, NJ, 1971.

Selgelid M.J. Ethics and Infectious Disease. Bioethics, 2005 , 19, 272-289.

SÈvE L. De quelle culture logico-philosophique la pensée du non-linéaire a-t-elle besoin? in: Emergence, complexité et dialéctique. Odile Jacob, Paris, 2005, 48-210.

Tausig M., Selgelid M.J., Subedi S. \& Subedi J. Taking sociology seriously: a new approach to the biothical problems of infectious disease. Sociology of Health and Illness, 2006, 28, 838-849.

TDR ReFERENCE GROUP ON MALARIA. Malaria. Nature Microbiology Reviews, 2004, 2, 276-277.

WheEler C. \& Berkley S. Initial lessons from public-private partnerships in drug and vaccine development. Bulletin of the World Health Organization, 2001, 79, 728-734.

Woolhouse M., Gowtage-Sequeria S. \& Evans B. T16: quantitative analysis of the characteristics of emerging and reemerging human pathogens. UK Government's Foresight project, Infectious Diseases: preparing for the futur, 2006, www.foresight.gov.uk 